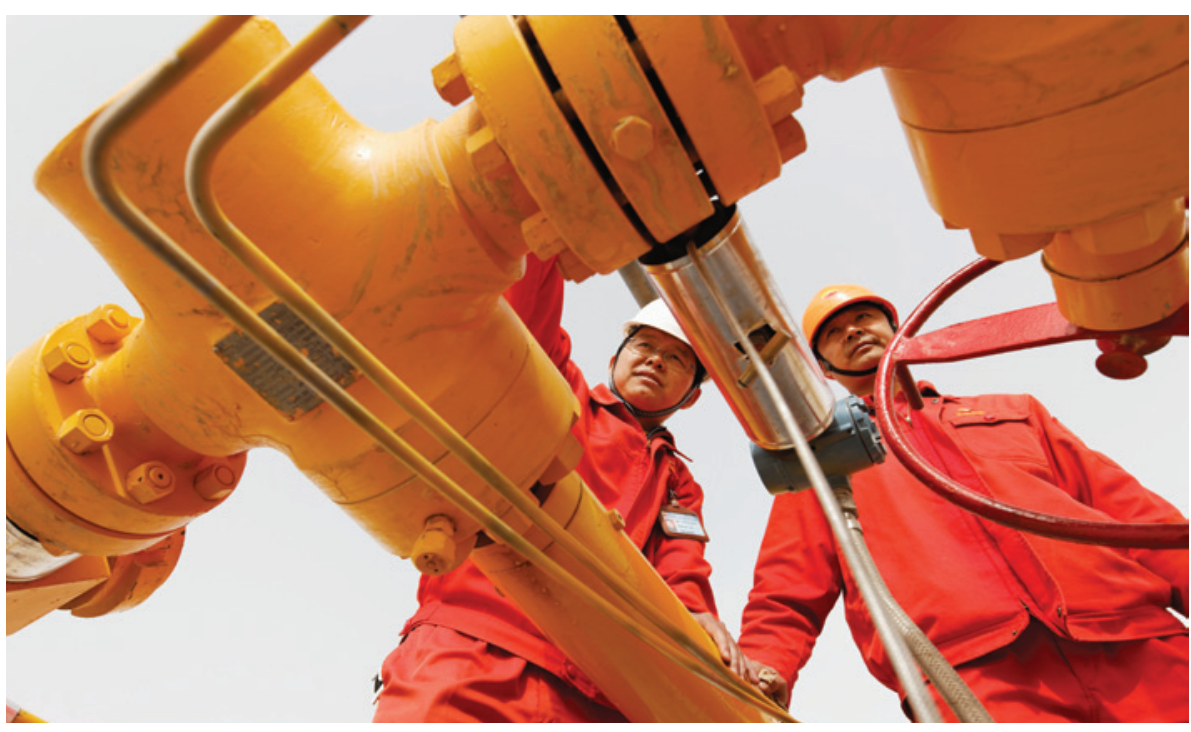

Technicians inspect a conventional gas well in China's Tarim basin, which is also rich in shale gas.

ENERGY

\title{
China slow to tap shale-gas bonanza
}

\section{Geology and infrastructure could impede development.}

\section{BY JEFF TOLLEFSON}

A fter more than a decade of spectacular growth fuelled by coal, China finds itself sitting on a bonanza of shale gas. Its reserves are the world's largest, beating even those of the United States. But developing this vast resource won't be easy, as a bidding last month for shale-gas leases made clear.

"The resource is huge," says Jane Nakano, a fellow of the Energy and National Security Program at the Center for Strategic and International Studies in Washington DC. "But the shale deposits are more complex than ours, and the above-ground challenges are probably even larger" than the geological ones.

To offset some of the coal use that contributes to its status as the world's largest greenhousegas emitter, China wants to boost natural gas from around $4 \%$ of the country's energy mix to $10 \%$ by 2020 . Much of that gas will be imported. But in March 2012, the Chinese government estimated the country's reserves at 25 trillion cubic metres, and an earlier estimate from the US Energy Information Administration was even larger. China's leaders resolved to boost annual shale-gas production from near zero today to at least 60 billion cubic metres by 2020 . The United States, by

\section{DNATURE.COM}

Explore the world's energy resources:

go.nature.com $/ 3 \mathrm{em} 370$ comparison, produced more than 150 billion cubic metres in 2010 .

There, the abundant, cheap gas has displaced coal as a fuel for power plants, contributing to a nearly $4 \%$ fall in the country's fossil-fuel emissions in 2012. If China could repeat that success, the emissions reductions could be globally significant. But its shale-gas auction - only the second so far - has bolstered scepticism. China's Ministry of Land and Resources awarded leases in 19 areas, mostly in the nation's central Sichuan Basin. Analysts were surprised to see national oil and gas companies,

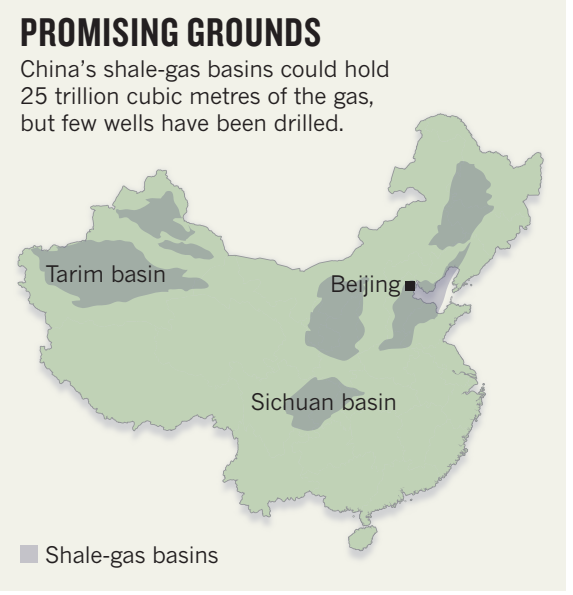

such as PetroChina and Sinopec, lose out to state-owned coal and utility companies, as well as to local government entities that have no expertise in the oil and gas arena.

Nakano says that the national oil firms may be playing it safe and did not truly compete to win. Price controls on natural gas may have reduced their appetite for risk, she says, and they have little experience with the hydraulic fracturing needed to release gas from shale.

Shu Jiang, a petroleum engineer who worked in China before moving to the University of Utah in Salt Lake City, is more optimistic, pointing out that major oil and gas companies are investing in shale-gas wells in areas already leased for conventional oil and gas development. He says that early results from the Sichuan basin are promising and that "China's vast shale resources will be extracted".

That is unlikely to happen quickly, however, says Julio Friedmann, chief energy technologist at the US energy department's Lawrence Livermore National Laboratory in California. "In the United States, it took 60 years and 200,000 wells" to lay the groundwork for the shale-gas revolution. China has drilled fewer than 100 wells, and its geology is different. Many of the Chinese shale formations have a high clay content, for instance, which makes them more pliable and less apt to fracture. Many are also deeper. "We simply have no idea about whether or not the geology is going to produce," Friedmann says.

The United States also has a unique abundance of small independent oil and gas companies with a tradition of risk-taking. China does not have such a 'wildcatter' culture, nor does it have the same mechanisms for developing and sharing geological data. Even a simple shortage of drilling rigs could slow things down.

Many expect that shale gas would at first be used in China as a feedstock for the chemical and fertilizer industries, reducing the use of gasified coal. In theory, that could lower the nation's annual carbon dioxide emissions by as much 100 million to 150 million tonnes, or roughly $1-1.5 \%$ of the nation's cumulative carbon emissions, Friedmann estimates.

Some of the climate benefits would be lost, however, if the wells leak methane - a potent greenhouse gas - and a shale-gas rush would raise the usual concerns about air and water quality. Water is scarce in the gas-rich Tarim basin (see 'Promising grounds'), whereas the Sichuan basin is heavily populated.

Groups such as the Clean Air Task Force, in Boston, Massachusetts, are encouraging companies and officials to adopt drilling practices that will minimize environmental impacts. Jonathan Banks, the force's climate-policy coordinator, says that the goal is to help China avoid mistakes made in the United States.

"China is going to be able to leapfrog over some of the stages that the United States went through," Banks says. "We are pushing to make sure that it is leapfrogging the environmental impacts as well." - SEE COMMENT P.307 